\title{
GERMINAÇÃO DE SEMENTES DE ROMÃZEIRAS (Punica granatum L.) DE ACORDO COM A CONCENTRAÇÃO DE GIBERELINA ${ }^{1}$
}

\author{
WILLIAM TAKATA², EWERTON GASPARETTO DA SILVA², \\ JAQUELINE MALAGUTTI CORSATO ${ }^{3}$, GISELA FERREIRA ${ }^{4}$
}

RESUMO - A romãzeira (Punica granatum L.) é fruteira de porte arbustivo, utilizada geralmente como planta ornamental e explorada quanto a suas características medicinais. Seus frutos apresentam cavidades internas onde estão alojadas numerosas sementes e sem a presença de endosperma. Estas sementes apresentam certa dificuldade para germinar, sendo que se conseguiu atingir porcentagens satisfatórias de germinação com a utilização de estratificação, que é processo necessário para a quebra da dormência fisiológica, já que altera o balanço hormonal, sobretudo os níveis de giberelina. O trabalho teve por objetivo avaliar a aplicação de concentrações de $\mathrm{GA}_{3}$ na germinação de sementes de Punica granatum em ambiente controlado com temperatura de $25^{\circ} \mathrm{C}$ e fotoperíodo de 12 horas de luz, sobre papel germitest. Adotou-se o delineamento inteiramente casualisado, com cinco tratamentos [concentrações de $\mathrm{GA}_{3}\left(0 ; 100 ; 200 ; 300\right.$ e $\left.400 \mathrm{mgL}^{-1}\right)$ ], quatro repetições de 25 sementes cada. Determinou-se durante a embebição a curva de aquisição de água das mesmas. As variáveis avaliadas foram porcentagem de germinação, tempo médio de germinação, índice de velocidade de germinação, índice de sincronização e frequência de germinação, comprimento médio total (parte aérea + parte radicular), massa da matéria fresca e seca das plântulas. A única variável que mostrou efeito das concentrações de $\mathrm{GA}_{3}$ foi o índice de velocidade de emergência. O tempo de embebição necessário para atingir máximo teor de água nas sementes de romãzeira (P.granatum) em água deionizada foi de quatro horas, sendo a embebição neste líquido o método eficaz para o processo germinativo, sem a necessidade de uso de giberelina.

Termos para indexação: Romã, regulador vegetal, giberelina.

\section{GERMINATION OF POMEGRANATE (Punica granatum L.) SEEDS UNDER GIBERELLIN CONCENTRATIONS}

\begin{abstract}
The pomegranate (Punica granatum L.) fruit tree is shrubby, often used as an ornamental plant and operated as its medicinal characteristics. Its fruits have internal cavities that host numerous seeds and without the presence of endosperm. These seeds are germinating some difficulty, and it was possible to achieve satisfactory percentages of germination using laminating process that is required for breaking of physiological dormancy, as alters hormone balance, particularly gibberellin levels. The study aimed to evaluate the application of $\mathrm{GA}_{3}$ concentrations on germination of seeds of Punica granatum in controlled temperature of $25^{\circ} \mathrm{C}$ and a photoperiod of 12 hours of light on paper germitest environment. We adopted the completely randomized design, with five treatments [GA ${ }_{3}$ concentrations $(0,100,200,300$ and $400 \mathrm{mg}$ $\left.\mathrm{L}^{-1}\right)$ ], four replicates of 25 seeds each. It was determined during the acquisition curve imbibition of water from the same. The variables evaluated were germination percentage, mean germination time, germination velocity index, index of synchronization and frequency of germination, total length (shoot + root), fresh weight and dry weight of seedlings. The only variable that showed the effect of concentrations of $\mathrm{GA}_{3}$ was the emergence rate index. The soaking time required to achieve maximum water content in the seeds of pomegranate tree (P. granatum) in deionized water was four hours, this soaking liquid effective method for the germination process, without the need to Gibberellin.
\end{abstract}

Index terms: Pomegranate, plant growth regulator, gibberellin.

1(Trabalho 269-13). Recebido em:05-08-2013. Aceito para publicação em: 27-02-2014.
2Doutorando em Agronomia (Horticultura), Departamento de Horticultura, Faculdade de Ciências Agronômicas, Unesp - Campus de
Botucatu. will.takata@gmail.com, wertogasparetto@hotmai.com
${ }^{3}$ Profa. Doutora, Centro de Ciências Biológicas e da Saúde (Botânica), Unioeste - Campus de Cascavel. E-mail: Jaque_corsato@
hotmail.com
${ }^{4}$ Profa. Doutora, Departamento de Botânica, Instituto de Biociências, Unesp - Campus de Botucatu. E-mail: gisela.unesp@yahoo.com.br

Rev. Bras. Frutic., Jaboticabal - SP, v. 36, n. 1, p.254-260, Março 2014 


\section{INTRODUÇÃO}

A romãzeira (Punica granatum L.) pertence à família Lythraceae, sendo fruteira de porte arbustivo, com provável centro de origem na Ásia, próximo à região do mediterrâneo. No Brasil, é encontrada comumente em parques e jardins, desempenhando papel ornamental e de propriedades medicinais (CORRÊA, 1978; GRUENWALD et al., 2000; MATOS, 2002).

Diversas propriedades medicinais são atribuídas a esta planta em diferentes partes da mesma, sendo que, por meio da análise fitoquímica, encontrou-se a presença de alcaloides e taninos gálicos na casca do caule e dos frutos, e nas folhas e sementes detectou-se a presença de ácidos graxos, principalmente o ácido púnico (SOUSA et al.,1991). Devido às diversas propriedades funcionais e nutracêuticas, o fruto tem ganhado grande destaque mundial (SUMNER et al., 2005).

Além de apresentar propriedades medicinais, os frutos de $P$. granatum são comestíveis, e seu cultivo apresenta-se promissor, principalmente em regiões áridas devido a sua tolerância à seca, entretanto um dos grandes obstáculos ao seu cultivo é a germinação de suas sementes (PIOTTO et al., 2003).

Rawat et al. (2010) trabalharam com estratificação de sementes de romã para posterior germinação e obtiveram, nos tratamentos de 25 e 30 dias de estratificação, resposta mais adequada, com germinação mais rápida e uniforme, bem como melhor crescimento na fase inicial de mudas em comparação ao controle (sem estratificação). A estratificação normalmente é uma técnica aplicada em sementes que apresentam dormência fisiológica, pois a mesma permite a modificação do balanço hormonal da semente, sobretudo nos níveis de giberelina endógena (PEREIRA; MAEDA, 1986).

$O$ processo de germinação é influenciado por diversos hormônios, existindo aqueles que atuam como promotores, e outros, como inibidores. As giberelinas, por exemplo, são consideradas como promotores da germinação, pois atuam na ativação do crescimento vegetativo do embrião, no enfraquecimento da camada do endosperma que envolve o embrião e restringe seu crescimento, assim como na mobilização de reservas energéticas. Além disso, as giberelinas podem atuar na síntese de proteínas e RNA específicos na germinação, tanto na quebra de dormência como no controle da hidrólise de reservas. Deste modo, elas estimulam a síntese de hidrólises como a $\alpha$-amilase, que degradam amido, liberando energia para o desenvolvimento dos embriões (TAIZ; ZEIGER, 2009).

Pela pequena importância no território nacional, trabalhos de pesquisas relacionados à produção de romã ainda são poucos, sobretudo na parte de propagação, onde trabalhos com germinação de sementes são essenciais, tanto para fins de melhoramento genético da espécie como para a própria propagação. Com base nessas informações sobre as sementes de romãzeira, o presente trabalho teve como objetivo estudar o efeito da imersão em solução com diferentes concentrações de $\mathrm{GA}_{3}$ na propagação sexuada desta espécie.

\section{MATERIAL E MÉTODOS}

As sementes de romãzeira ( $P$. granatum L.) foram extraídas de frutos fisiologicamente maduros, provenientes de pomar comercial. $\mathrm{O}$ arilo foi retirado, friccionando-se as sementes em peneira com água corrente, após período de fermentação de 72 horas e posterior secagem das sementes à sombra, com temperatura ambiente de $25^{\circ} \mathrm{C} \pm 2^{\circ} \mathrm{C}$ sobre papel mata-borrão durante sete dias.

Foi realizada uma curva de aquisição de água em delineamento inteiramente casualizado, contendo 100 sementes divididas em 4 repetições, onde primeiramente se realizou a determinação do teor de água inicial das sementes deixandoas 24 horas em estufa com circulação de ar em temperatura de $105^{\circ} \mathrm{C} \pm 2^{\circ} \mathrm{C}$, pesando-as em balança de precisão. A segunda etapa constituiu na imersão das sementes, em água deionizada, sendo utilizado sistema de oxigenação. A retirada das sementes foi realizada a cada 30 minutos, durante as 4 primeiras horas, secando-as posteriormente em papel-toalha para fazer a medição da massa da matéria fresca das mesmas (BRASIL, 2009). Decorrido esse período, o procedimento foi realizado em intervalos de 4 horas até atingir 24 horas, e desta forma determinou-se o tempo em que as sementes ficariam imersas nas soluções.

O delineamento experimental utilizado foi o inteiramente casualizado, contendo cinco concentrações de $\mathrm{GA}_{3}$ divididas em quatro repetições, e cada parcela foi constituída por 25 sementes. $\mathrm{O}$ tratamento das sementes foi realizado imergindoas na solução de água deionizada e de $\mathrm{GA}_{3}$, nas concentrações de $0,100,200,300$ e $400 \mathrm{mg} \mathrm{L}^{-1}$, durante quatro horas. $\mathrm{O}$ produto comercial utilizado como fonte do $\mathrm{GA}_{3}$ foi o Pro-Gibb ${ }^{\circledR}$.

$\mathrm{O}$ experimento foi conduzido em câmara de germinação do tipo B.O.D. com temperatura constante de $25^{\circ} \mathrm{C}$ e fotoperíodo de 12 horas, onde as sementes foram dispostas sobre papel mata-borrão 
umedecido com água, na proporção de 2,5 vezes a massa seca das sementes, mantidas em caixas plásticas transparentes (Brasil, 2009).

A contagem diária das sementes foi realizada durante 60 dias, e após este período, foram calculados porcentagem, tempo médio (LABORIAU, 1983), índice de velocidade (SILVA; NAKAGAWA, 1995), frequência e sincronização da germinação (LABORIAU; AGUDO, 1987), assim como a medição do comprimento de cinco plântulas ao final do experimento, por repetição, utilizando-se de paquímetro digital, e a pesagem em balança de precisão das massas da matéria fresca e seca das plântulas que foram deixadas durante 4 dias em estufa com circulação de ar, em temperatura de $60^{\circ} \mathrm{C}$.

As avaliações da porcentagem de germinação foram realizadas através de contagem diária do número de sementes germinadas, sendo padronizada como germinada aquela que apresentou, pelo menos, dois milímetros de raiz primária (HÁDAS, 1976).

Os dados foram submetidos ao teste de normalidade e homogeneidade das variâncias, não apresentando necessidade de transformação dos dados para serem submetidos à análise de variância (teste F); e as médias, comparadas pelo teste de Tukey, ao nível de $5 \%$ de probabilidade.

\section{RESULTADOS E DISCUSSÃO}

As sementes possuíam teor inicial de água por volta de $9 \%$, elevando-se esse valor rapidamente durante as duas primeiras horas e aumentando-se de forma mais lenta até atingir estabilidade, por volta das quatro horas, caracterizando-se como a fase I da germinação de embebição, na qual o teor de água ficou em torno dos 50\% (Figura 1), e a partir deste período, as sementes possuem características semelhantes às encontradas na fase II (BEWLEY; BLACK, 1994).

A entrada de água na semente, na fase I, ocorre independentemente da viabilidade da semente, pois este é um processo físico apenas, sendo a velocidade determinada pelo potencial matricial (BORGHETTI, 2004); dessa forma, o período de duração da fase I depende da espécie. O período curto da fase I que as sementes de romãzeiro apresentam é uma característica vantajosa, pois, caso haja necessidade de algum tratamento pré-germinativo, este é empregado de forma rápida.

$\mathrm{O}$ aumento na concentração de $\mathrm{GA}_{3}$ não alterou significativamente a porcentagem de germinação das sementes, encontrando-se variação entre $99 \%$ e $76 \%$. O mesmo ocorreu para o tempo médio de germinação e o índice de sincronização em sementes, cujas médias variaram de 32,6 a 26,48 dias e 2,88 a 3,15 (Tabela 1 ).

O balanço hormonal das sementes de romãzeiro, provavelmente, apresenta-se favorável à germinação, o que pode explicar o fato de 0 fornecimento de $\mathrm{GA}_{3}$ não ter influenciado na porcentagem de germinação, assim como no tempo médio de germinação e na sincronização.

Todavia, a utilização de $\mathrm{GA}_{3}$ durante a embebição apresentou diferença estatística apenas no índice de velocidade de germinação, sendo que o maior valor foi obtido com $100 \mathrm{mg} \mathrm{L}^{-1}$, sem diferença das sementes não tratadas, decrescendo à medida que se elevou a concentração, chegando a ser 53\% menor na concentração de $300 \mathrm{mg} \mathrm{L}^{-1}$.

A diminuição nos valores de IVG com aumento da concentração de $\mathrm{GA}_{3}$ pode estar relacionada ao fato de que esta giberelina, quando diluída em água, altera o potencial osmótico da solução, consequentemente modificando o potencial hídrico, e dessa forma dificultando a entrada de água na semente. Neste sentido, o tempo em que as sementes deveriam permanecer embebidas para máxima hidratação teria de ser maior com a elevação da concentração desta solução. Outro aspecto que deve ser evidenciado é que, provavelmente, as sementes de romãzeiro, quando submetidas à soluções com concentrações mais elevadas de $\mathrm{GA}_{3}$, podem ter sofrido fitotoxidez devido ao desbalanço hormonal.

O comprimento médio das plântulas e a massa da matéria fresca e seca não sofreram ação da aplicação de $\mathrm{GA}_{3}$ (Tabela 2). Esperava-se que as sementes que germinaram primeiro obtivessem os maiores valores biométricos, mas esse fato não foi observado. Possivelmente, o tempo em que as plântulas permaneceram em gerbox após germinação foi demasiado, possibilitando que todas as plântulas atingissem o tamanho máximo, pois, como não havia nutrientes no meio, as plântulas cresceram, utilizando-se apenas de suas reservas, supondo-se que estas eram praticamente semelhantes.

Em todos os tratamentos, os polígonos apresentaram tendência polimodal quanto à frequência relativa de germinação (Figura 2), o que os caracteriza como desuniformes, com a presença de vários picos. A frequência de germinação também está relacionada ao tempo médio de germinação e o índice de velocidade de germinação, apresentando-se nas Figuras $2 \mathrm{~A}$ e $2 \mathrm{C}$ maior deslocamento dos pontos para a esquerda, pois está relacionado ao maior índice de velocidade de germinação, assim como são mais curtas do que os outros tratamentos, devido ao menor tempo médio de germinação, mesmo não 
apresentando diferença entre as concentrações.

Em plantas superiores, a dormência e a germinação de sementes são complexos processos fisiológicos influenciados por muitos fatores, como a genética, fisiologia e bioquímica, que apontam a giberelina como uma das principais responsáveis para ativação das rotas metabólicas para iniciar esse processo (YAMAGUCHI; NAMBARA, 2006). Aoyama et al. (1996), estudando sementes de lavanda, e Ynoue et al. (1999), com kiwi, conseguiram aumentar significativamente a porcentagem de germinação, assim como diminuir o tempo médio de germinação, utilizando 100 e $150 \mathrm{mg} \mathrm{L}^{-1}$ de GA, respectivamente. Resultados semelhantes foram obtidos por Aragão et al. (2001) com milho-doce e Leonel et al. (1998) estudando mamoeiro, utilizando $100 \mathrm{mg} \mathrm{L}^{-1}$ de $\mathrm{GA}_{3}$ nos dois trabalhos. Porém, quando comparado aos resultados do presente trabalho (Tabela 1), estes mostraram-se contrários, pois na Tabela 1 verificou-se semelhança estatística, sugerindo-se que provavelmente o balanço hormonal da semente foi naturalmente favorável.

Lopes et al. (2001), trabalhando também com sementes de romãzeiro sem aplicação de qualquer tratamento para estimular o processo germinativo, obtiveram germinação inferior a 5\%. Rawat et al. (2010), com a mesma fruteira, conseguiram $40 \%$ de germinação. Analisando-se a Tabela 1, verificou-se que as sementes em cujo tratamento não foi aplicado $\mathrm{GA}_{3}$ obtiveram $99 \%$ de sementes germinadas. Uma possível hipótese para esse resultado é o fato de que as sementes do presente estudo foram embebidas em água, o que permitiu mais rápida ativação do processo germinativo. Willan (1990), citado por Eira et al. (1993), sugeriu que a embebição das sementes contribui para aumentar a porcentagem e a velocidade de germinação de sementes. Ferreira e Gentil (2006) concluíram que a embebição das sementes se apresenta como método que acelera e aumenta a germinação, porém ainda existem resultados controversos como os relatados por Firmino et al. (1997), em cajá, Adegas et al. (2003), com picão-preto, e Andrade et al. (2006), trabalhando com camu-camu.

Além disso, existe a questão genética, pois as sementes foram obtidas de plantas- matrizes diferentes daquelas ressaltadas pelos autores, com baixo percentual de germinação

TABELA 1 - Germinação (\%), TMG - tempo médio de germinação (dias), IVG - índice de velocidade de germinação e U - índice de sincronização em sementes de romãzeira (Punica granatum) de acordo com a concentração de $\mathrm{GA}_{3}\left(\mathrm{mg} \mathrm{L}^{-1}\right)$.

\begin{tabular}{ccccc}
\hline $\begin{array}{c}\text { Concentração de GA } \\
\left(\mathrm{mg} \mathrm{L}^{-1}\right)\end{array}$ & $\begin{array}{c}\text { Germinação } \\
(\%)\end{array}$ & $\begin{array}{c}\text { TMG } \\
(\text { dias })\end{array}$ & IVG & U \\
\hline 0 & $99,0 \mathrm{~ns}$ & $26,48 \mathrm{~ns}$ & $8,05 \mathrm{ab}^{*}$ & $2,88 \mathrm{~ns}$ \\
\hline 100 & 94,0 & 27,81 & $10,27 \mathrm{a}$ & 3,15 \\
200 & 93,0 & 26,85 & $5,61 \mathrm{~b}$ & 3,10 \\
300 & 89,0 & 31,63 & $5,48 \mathrm{~b}$ & 3,14 \\
400 & 76,0 & 32,6 & $5,68 \mathrm{~b}$ & 3,01 \\
\hline CV $(\%)$ & 8,96 & 6,33 & 11,57 & 6,84 \\
\hline
\end{tabular}

*Médias seguidas de letras iguais na coluna não diferem entre si, pelo teste de Tukey a $5 \%$. ns. Não significativo pelo teste F.

TABELA 2 - Comprimento da plântula (mm), massa da matéria fresca (MF) e seca (MS) (g) de plântulas de romãzeira ( $P$. granatum) em função de concentrações de $\mathrm{GA}_{3}\left(\mathrm{mg} \mathrm{L}^{-1}\right)$.

\begin{tabular}{cccc}
\hline Concentração de $\mathrm{GA}_{3}\left(\mathrm{mg} \mathrm{L}^{-1}\right)$ & Comprimento & MF & MS \\
\hline 0 & $51,98^{\mathrm{ns}}$ & $0,045^{\mathrm{ns}}$ & $0,0050^{\mathrm{ns}}$ \\
100 & 59,26 & 0,046 & 0,0065 \\
200 & 47,14 & 0,044 & 0,0063 \\
300 & 55,42 & 0,045 & 0,0076 \\
400 & 36,89 & 0,033 & 0,0075 \\
\hline $\mathrm{CV}(\%)$ & 20,59 & 19,14 & 22,21 \\
\hline
\end{tabular}

ns - não significativo pelo teste $\mathrm{F}$. 


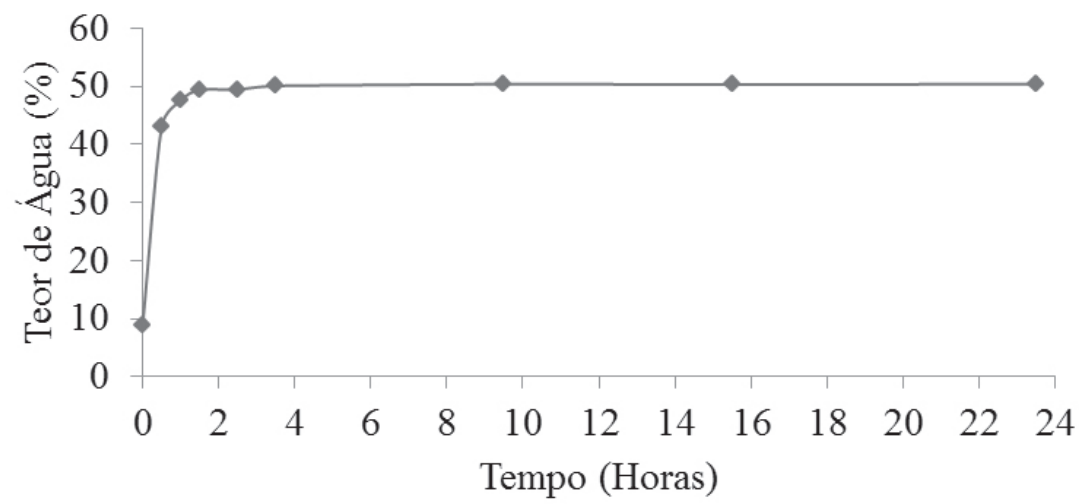

FIGURA 1 - Curva de aquisição de água de sementes de romãzeira (Punica granatum), imersas em água deionizada. Botucatu - SP.

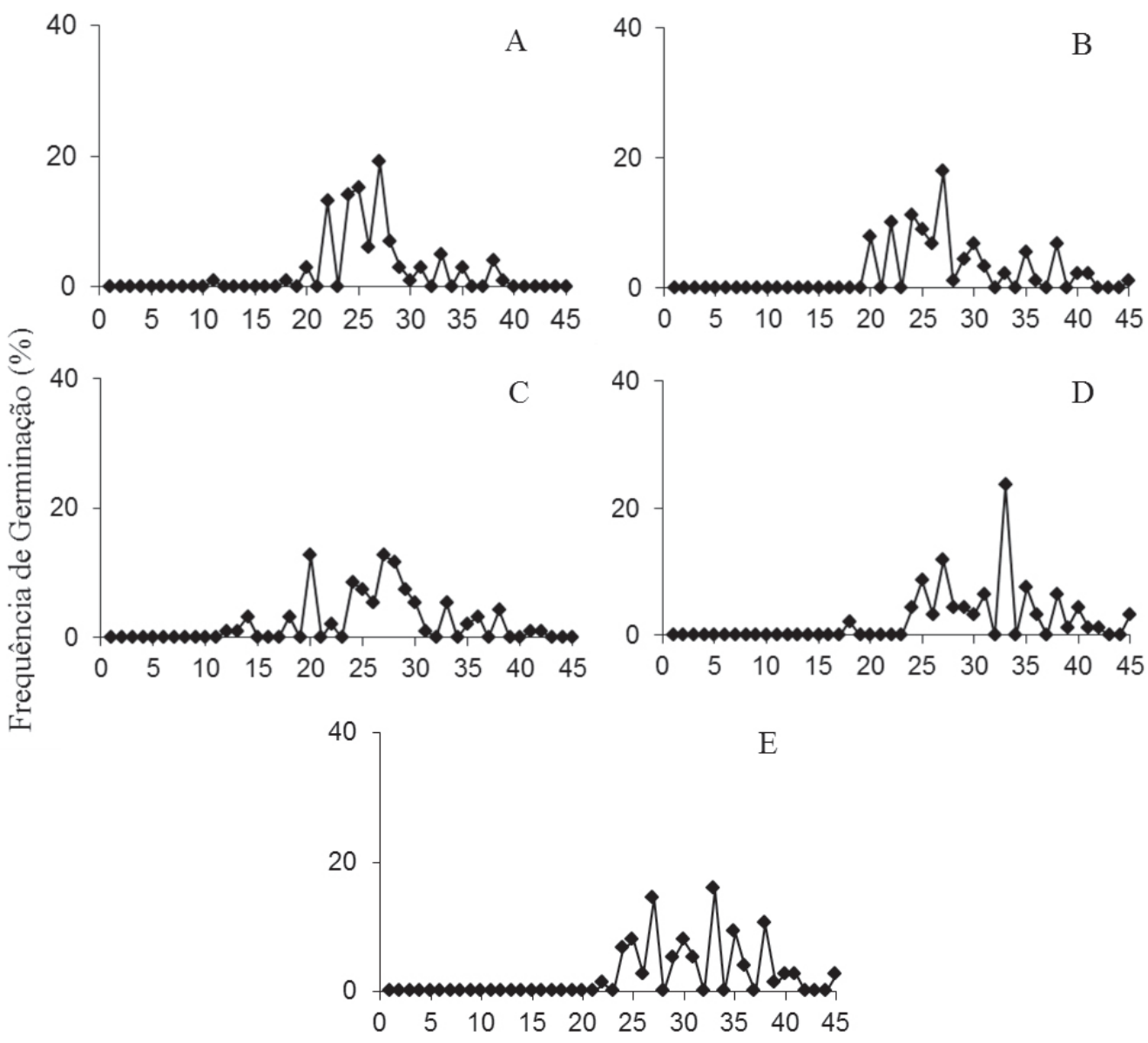

FIGURA 2 - Frequência relativa de germinação das sementes de romãzaeira (Punica granatum) embebidas nas concentrações de $\mathrm{GA}_{3}$ de $0 \mathrm{mgL}^{-1}$ (A), $100 \mathrm{mgL}^{-1}$ (B), $200 \mathrm{mgL}^{-1}$ (C), $300 \mathrm{mgL}^{-1}$ (D) e $400 \mathrm{mgL}^{-1}(\mathrm{E})$. 


\section{CONCLUSÕES}

A imersão das sementes de romãzeira (Punica granatum) em água apresenta-se como método eficaz para o processo germinativo, demonstrando não haver necessidade da utilização de giberelina.

\section{AGRADECIMENTOS}

À CAPES e à FAPESP, pela concessão de bolsa aos autores, ao PPGA - Horticultura, pelo apoio, e ao pesquisador Dr. Nobuyoshi Narita, pelo fornecimento das sementes.

\section{REFERENCIAS}

ADEGAS, F. S.; VOLL, E.; PRETE, C. E. C. Embebição e germinação de sementes de picão-preto (Bidens pilosa). Planta Daninha, Viçosa, MG, v. 21, n. 1, p. 21-25, 2003.

ANDRADE, R. A.; JESUS, N.; MARTINS, A. B. G. Embebição e germinação de sementes de camucamu. Acta Scientia Agronômica, Maringá, v. 28, n. 4, p. 499-501, 2006.

ARAGÃO, C. A. et al. Fitorreguladores na germinação de sementes e vigor de plântulas de milho superdoce. Revista Brasileira de Sementes, Viçosa, MG, v. 23, n. 1, p. 62-67, 2001.

AOYAMA, E.M.; ONO, E.O.; FURLAN, M.R. Estudo da germinação de sementes de lavanda (Lavandula angustifolia Miller). Scientia Agricola, Piracicaba, v. 53, n. 2/3, maio 1996. Disponível em: <http://www. scielo.br/scielo.php?script $=$ sci arttext\&pid $=\mathrm{S} 0103$ 90161996000200013\&lng=pt\&nrm $=$ iso $>$. Acesso em: 30 abr. 2013.

BEWLEY, J. D.; BLACK, M. Seeds, physiology of development and germination. $2^{\text {nd }}$ ed. New York: Plenum Press, 1994. 445p.

BORGES, E. E. L.; BORGES, R. C. G.; CANDIDO, J. F.; GOMES J. P. Comparação de métodos de quebra de dormência em sementes de copaíba. Revista Brasileira de Sementes, Viçosa, MG, v. 4, n. 1, p. 9-12, 1982.

BRASIL. Ministério da Agricultura. Regra de análise de sementes. Brasília: Departamento de Produção Vegetal, 2009. 398p.
CORREAA, P. M. Dicionário das plantas úteis do Brasil e das exóticas cultivadas. Rio de Janeiro: Imprensa Nacional, 1978. v. 5, p.609-610.

CUSTÓDIO, C. C.; NETO, N. B. M.; ITO, H. M.; VIVIAN, M. R. Efeito da submersão em água de sementes de feijão na germinação e no vigor. Revista Brasileira de Sementes, Viçosa, MG, v. 24, n. 2, p. 49-54, 2002.

EIRA, M. T. S.; FREITAS, R. W. A.; MELO, C. M. C. Superação da dormência de sementes de Enterolobium contortisiliquum (Vell.) Morong Leguminosae. Revista Brasileira de Sementes, Viçosa, MG, v.15, n.2, p.177-181, 1993.

FERREIRA, S. A. N.; GENTIL, D. F. O. Extração, embebição e germinação de sementes de tucumã (Astrocaryum aculeatum). Acta Amazônica, Manaus, v. 36, n. 2, p. 141-146, 2006.

FIRMINO, J. L.; ALMEIDA, M. C.; TORRES, S. B. Efeito da escarificação e da embebição sobre a emergência e desenvolvimento de plântulas de cajá (Spondias lutea L.). Revista Brasileira de Sementes, Viçosa, MG, v. 19, n. 1, p. 125-128, 1997.

GRUENWALD, J.; BRENDLER, T.; JAENICKKE, $\mathrm{C}$. Physicians desk references for herbal medicines. New Jersey: Medical Economics, 2000. 858p.

HADAS, A. Water uptake and germination of leguminous seeds under changing external water potencial in osmotic solution. Journal of Experimental Botany, Oxford, v. 27, p. 480-489, 1976.

LABORIAU, L. G. A germinação das sementes. Washington: Secretaria Geral da Organização dos Estados Americanos, 1983.174p.

LABOURIAU, L.G.; AGUDO, M. On the physiology of seed germination in S. hispanica L. Temperature effects. Anais da Academia Brasileira de Ciências, Rio de Janeiro, v. 59, n. 1, p. 37-56, 1987.

LEONEL, S.; ONO, E.O.; RODRIGUES, J. D. Influência da alternância de temperaturas e tratamentos com $\mathrm{GA}_{3}$, na germinação de sementes de mamoeiro. Semina: Ciências Agrárias, Londrina, v. 19, n. 1, p. 68-72, 1998. 
LOPES, K. P. et al. Comportamento de sementes de romã (Punica granatum L.) submetidas à fermentação e secagem. Revista Brasileira de Fruticultura, Jaboticabal, v. 23, n. 2, p. 369-372, 2001.

MATOS, F.J.A. Plantas medicinais - guia de seleção e emprego de plantas usadas em fitoterapia no nordeste do Brasil. Fortaleza: Imprensa Universitária/UFC, 2002. 344p.

PEREIRA, M. F. D. A.; MAEDA, J.A. Environmental and endogenous control of germination of Vitis vinifera seeds. Seed Science and Technology, Zurich, v.14, p. 227-235, 1986.

PIOTTO, B.; et al., Fact sheets on the propagation of mediterranean trees and shrubs from seed. In: PIOTTO, B.; DI NOI, A. (Ed.). Seed propagation of mediterranean trees and shrubs. Rome: Agency for the Protection of the Environment and for Technical Services, 2003. p.11-51

RAWAT, J.M.S.; TOMAR, Y.K.; RAWAT, V. Effect of stratification on seed germination and seedling performance of wild pomegranate. Journal of American Science, Stanford, v. 6, n. 5, p. 97-99, 2010 .

SILVA, J.B.; NAKAGAWA, J. Estudos de fórmulas para cálculo de velocidade de germinação. Informativo Abrates, Curitiba, v.5, p. 62-73, 1995.

SOUSA, M.P.; MATOS, M.E.O; MATOS, F.J.A. Constituintes químicos de plantas medicinais brasileiras. Fortaleza: Imprensa Universitária/UFC, 1991. 416p.
SUMNER, M. D.; ELLIOTT-ELLER, M.; WEIDNER, G.; DAUBENMIER, J. J.; CHEW, M. H.; MARLIN, R. Effects of pomegranate juice consumption on myocardial perfusion in patients with coronary heart disease. Journal of Cardiology, Okayama, v. 96, p. 810-814, 2005.

TAIZ. L.; ZEIGER, E. Fisiologia vegetal. Porto Alegre: Artmed, 2009. 819p.

YAMAGUCHI, S.; NAMBARA, E. Seed development and germination. In: HEDDEN, P.; THOMAS, S. G. Plant hormone signaling. Oxford: Blackwell Publishing, 2006. p.311-338.

YNOUE, C. K.; ONO, E. O.; MARCHI, L. de O. S. Efeito do $\mathrm{GA}_{3}$ na germinação de sementes de kiwi (Actinidia chinensis Planch.). Scientia Agricola, Piracicaba, v. 56, n. 1, 1999. Disponível em: $<$ http://www.scielo.br/scielo.php?script $=$ sci arttext\&pid $=$ S0103-90161999000100002\&lng $=$ pt

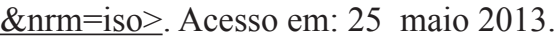

ZENG, Y.; WU, Y.; AVIGNE, W. T.; KOCH, K. E. Rapid repression of maize invertases by low oxygen: invertase/sucrose synthase balance, sugar signaling potential, and seedling survival. Plant Physiology, Rockville, v. 121, n. 2, p. 599-608, 1999. 